\title{
Detections and SIR simulations of the COVID-19 pandemic waves in Ukraine
}

https://doi.org/10.1515/cmb-2020-0117

Received February 21, 2021; accepted April 22, 2021

Abstract: Background. Unfortunately, the COVID-19 pandemic is still far from stabilizing. Of particular concern is the sharp increase in the number of diseases in June-July, September-October 2020 and FebruaryMarch 2021. The causes and consequences of this sharp increase in the number of cases are still waiting for their researchers, but there is already an urgent need to assess the possible duration of the pandemic, the expected number of patients and deaths. Correct simulation of the infectious disease dynamics needs complicated mathematical models and many efforts for unknown parameters identification. Constant changes in the pandemic conditions (in particular, the peculiarities of quarantine and its violation, situations with testing and isolation of patients) cause various epidemic waves, lead to changes in the parameter values of the mathematical models.

Objective. In this article, pandemic waves in Ukraine will be detected, calculated and discussed. The estimations for durations and final sizes of the epidemic waves will be presented.

Methods. We propose a simple method for the epidemic waves detection based on the differentiation of the smoothed number of cases. We use the generalized SIR (susceptible-infected-removed) model for the dynamics of the epidemic waves. The known exact solution of the SIR differential equations and statistical approach were used. We will use different data sets for accumulated number of cases in order to compare the results of simulations and predictions.

Results. Nine pandemic waves were detected in Ukraine and corresponding optimal values of the SIR model parameters were identified. The number of cases and the number of patients spreading the infection versus time were calculated. In particular, the pandemic in Ukraine probably began in January 2020. If current trends continue, the end of the pandemic should be expected no earlier than in summer 2021.

Conclusions. The differentiation of the smoothed number of cases, the SIR model and statistical approach to the parameter identification are helpful to select COVID-19 pandemic waves and make some reliable estimations and predictions. The obtained information will be useful to regulate the quarantine activities, to predict the medical and economic consequences of the pandemic.

Keywords: COVID-19 pandemic, COVID-19 epidemic in Ukraine, mathematical modeling of infection diseases, SIR model, parameter identification, statistical methods

MSC: 34A34, 62J05, 92C60

\section{Introduction}

Here we consider the COVID-19 pandemic dynamics in Ukraine with the use of official WHO data sets about the confirmed number of cases, [1]; Ukrainian national statistics (UNS) [2, 3] and COVID-19 Data Repository by the Center for Systems Science and Engineering (CSSE) at Johns Hopkins University (JHU), [4]. The classical SIR model, connecting the number of susceptible $S$, infected and spreading the infection $I$ and removed $R$ persons, was developed in $[5,6,7]$. The unknown parameters of this model can be estimated with the use of the cumulative number of cases $V=I+R$ and the statistics-based method of parameter identification $[8,9]$.

${ }^{\star}$ Corresponding Author: Igor Nesteruk: Institute of Hydromechanics. National Academy of Sciences of Ukraine, National Technical University of Ukraine “Igor Sikorsky Kyiv Polytechnic Institute”, E-mail: inesteruk@yahoo.com 
This approach was used in $[9,10,11,12,13,14,15,16,17,18,19,20]$ to estimate the first waves of pandemic dynamics in Ukraine, the city of Kyiv, China, the Republic of Korea, Italy, Austria, Spain, Germany, France, the Republic of Moldova, the UK, USA and in the world. Usually the number of cases registered during the initial period of an epidemic is not reliable, since many infected persons are not detected. That is why the correct estimations of epidemic parameters can be done with the use of data sets obtained for later periods of the epidemic when the number of detected cases is closer to the real one. On the other hand, changes in quarantine conditions, human behavior, pathogen activity, weather etc. can cause changes in the course of the pandemic, namely the so-called epidemic waves. The mathematical simulation of these waves needs development of some criteria of the waves detection, modification of models and methods of parameter identification.

In this paper simple criteria for identification of next pandemic waves will be discussed. The SIR model and the parameter identification procedure will be modified in order to simulate next waves of the pandemic. The results of calculations for nine waves of the Covid-19 pandemic in Ukraine will be presented and discussed.

\section{Materials and Methods}

\subsection{Data}

The information regarding the accumulated numbers of confirmed COVID-19 cases $V_{j}$ in Ukraine from WHO daily situation reports, [1]; UNS [2, 3] (denoted by $V_{j}$ and $V_{j 1}$ ) and JHU [4] (denoted $V_{j 2}$ ) is presented in Tables 1-3. The corresponding moments of time $t_{j}$ ( measured in days, zero point corresponds to January 20, 2020) are also shown in Tables 1 and 2. All these data sets were used for the identification of the epidemic waves. For SIR simulations were used only some time periods corresponding to specific waves. Other values were used only for verifications of SIR simulations.

\subsection{Epidemic waves detection}

Changes in quarantine conditions, human behavior, pathogen activity, weather etc. can cause changes in the epidemic dynamics, namely the so-called epidemic waves. The simplest way of their detection is to find some changes in the dependences of the number of registered cases on time. Since the number of cases is random, its time dependence needs some smoothing. We can use the method proposed in $[19,20]$ :

$$
\bar{V}_{i}=\frac{1}{7} \sum_{j=i-3}^{j=i+3} V_{j},
$$

and the derivatives of the smoothed values

$$
\begin{gathered}
\left.\frac{d \bar{V}}{d t}\right|_{t=t_{i}} \approx \frac{1}{2}\left(\bar{V}_{i+1}-\bar{V}_{i-1}\right) \\
\left.\frac{d^{2} \bar{V}}{d t^{2}}\right|_{t=t_{i}} \approx \bar{V}_{i+1}-2 \bar{V}_{i}+\bar{V}_{i-1}
\end{gathered}
$$

in order to detect the changes in epidemics dynamics. Some mathematical background of this method can be found in $[21,22,23,24]$.

\subsection{Generalized SIR model}

The generalized SIR model for an infectious disease [20] relates the number of susceptible persons $S$ (persons who are sensitive to the pathogen and not protected); the number of infected is $I$ (persons who are sick and 
Table 1: Official cumulative numbers of confirmed cases in Ukraine in spring and summer 2020, $[1,2,3]$

\begin{tabular}{|c|c|c|c|c|c|c|c|c|}
\hline $\begin{array}{l}\text { Day in April, } \\
\text { May, and June } \\
2020\end{array}$ & $\begin{array}{c}\text { Time } \\
\text { in days } \\
t_{j}\end{array}$ & $\begin{array}{c}\text { Number } \\
\text { of cases, } \\
V_{j}\end{array}$ & $\begin{array}{c}\text { Day in } \\
\text { June and } \\
\text { July } 202\end{array}$ & $\begin{array}{c}\text { Time } \\
\text { in days } \\
t_{j}\end{array}$ & $\begin{array}{c}\text { Number } \\
\text { of cases, } \\
V_{j}\end{array}$ & $\begin{array}{l}\text { Day in July } \\
\text { and August } \\
2020\end{array}$ & $\begin{array}{c}\text { Time } \\
\text { in days } \\
t_{j}\end{array}$ & $\begin{array}{c}\text { Number } \\
\text { of cases, } \\
V_{j}\end{array}$ \\
\hline 29 & 100 & 10406 & 10 & 142 & 29070 & 22 & 184 & 61851 \\
\hline 30 & 101 & 10861 & 11 & 143 & 29753 & 23 & 185 & 62823 \\
\hline 1 & 102 & 11411 & 12 & 144 & 30506 & 24 & 186 & 63929 \\
\hline 2 & 103 & 11913 & 13 & 145 & 31154 & 25 & 187 & 64849 \\
\hline 3 & 104 & 12331 & 14 & 146 & 31810 & 26 & 188 & 65656 \\
\hline 4 & 105 & 12697 & 15 & 147 & 32476 & 27 & 189 & 66575 \\
\hline 5 & 106 & 13184 & 16 & 148 & 33234 & 28 & 190 & 67597 \\
\hline 6 & 107 & 13691 & 17 & 149 & 34063 & 29 & 191 & 68794 \\
\hline 7 & 108 & 14195 & 18 & 150 & 34984 & 30 & 192 & 69884 \\
\hline 8 & 109 & 14710 & 19 & 151 & 35825 & 31 & 193 & 71056 \\
\hline 9 & 110 & 15232 & 20 & 152 & 36560 & 1 & 194 & 72168 \\
\hline 10 & 111 & 15648 & 21 & 153 & 37241 & 2 & 195 & 73158 \\
\hline 11 & 112 & 16023 & 22 & 154 & 38074 & 3 & 196 & 74219 \\
\hline 12 & 113 & 16425 & 23 & 155 & 39014 & 4 & 197 & 75490 \\
\hline 13 & 114 & 16847 & 24 & 156 & 40009 & 5 & 198 & 76808 \\
\hline 14 & 115 & 17330 & 25 & 157 & 41117 & 6 & 199 & 78261 \\
\hline 15 & 116 & 17858 & 26 & 158 & 42065 & 7 & 200 & 79750 \\
\hline 16 & 117 & 18291 & 27 & 159 & 42982 & 8 & 201 & 80949 \\
\hline 17 & 118 & 18616 & 28 & 160 & 43628 & 9 & 202 & 81957 \\
\hline 18 & 119 & 18876 & 29 & 161 & 44334 & 10 & 203 & 83115 \\
\hline 19 & 120 & 19230 & 30 & 162 & 44998 & 11 & 204 & 84548 \\
\hline 20 & 121 & 19706 & 1 & 163 & 45888 & 12 & 205 & 86140 \\
\hline 21 & 122 & 20148 & 2 & 164 & 46763 & 13 & 206 & 87872 \\
\hline 22 & 123 & 20580 & 3 & 165 & 47677 & 14 & 207 & 89719 \\
\hline 23 & 124 & 20986 & 4 & 166 & 48500 & 15 & 208 & 91356 \\
\hline 24 & 125 & 21245 & 5 & 167 & 49043 & 16 & 209 & 92820 \\
\hline 25 & 126 & 21584 & 6 & 168 & 49607 & 17 & 210 & 94436 \\
\hline 26 & 127 & 21905 & 7 & 169 & 50414 & 18 & 211 & 96403 \\
\hline 27 & 128 & 22382 & 8 & 170 & 51224 & 19 & 212 & 98537 \\
\hline 28 & 129 & 22811 & 9 & 171 & 52043 & 20 & 213 & 100643 \\
\hline 29 & 130 & 23294 & 10 & 172 & 52843 & 21 & 214 & 102971 \\
\hline 30 & 131 & 23672 & 11 & 173 & 53521 & 22 & 215 & 104958 \\
\hline 31 & 132 & 24002 & 12 & 174 & 54133 & 23 & 216 & 106757 \\
\hline 1 & 133 & 24340 & 13 & 175 & 54771 & 24 & 217 & 108415 \\
\hline 2 & 134 & 24823 & 14 & 176 & 55607 & 25 & 218 & 110085 \\
\hline 3 & 135 & 25411 & 15 & 177 & 56455 & 26 & 219 & 112059 \\
\hline 4 & 136 & 25964 & 16 & 178 & 57264 & 27 & 220 & 114497 \\
\hline 5 & 137 & 26514 & 17 & 179 & 58111 & 28 & 221 & 116978 \\
\hline 6 & 138 & 26999 & 18 & 180 & 58842 & 29 & 222 & 119074 \\
\hline 7 & 139 & 27462 & 19 & 181 & 59493 & 30 & 223 & 121215 \\
\hline 8 & 140 & 27856 & 20 & 182 & 60166 & 31 & 224 & 123303 \\
\hline 9 & 141 & 28381 & 21 & 183 & 60995 & & & \\
\hline
\end{tabular}


Table 2: Official cumulative numbers of confirmed cases in Ukraine in autumn 2020, $[2,3]$

\begin{tabular}{|c|c|c|c|c|c|c|c|c|}
\hline $\begin{array}{l}\text { Day in } \\
\text { September and } \\
\text { October } \\
2020\end{array}$ & $\begin{array}{c}\text { Time } \\
\text { in days } \\
t_{j}\end{array}$ & $\begin{array}{c}\text { Number } \\
\text { of cases in } \\
\text { Ukraine } \\
V_{j}\end{array}$ & $\mid \begin{array}{c}\text { Day in October } \\
\text { and November } \\
2020\end{array}$ & $\begin{array}{c}\text { Time } \\
\text { in days } \\
t_{j}\end{array}$ & $\begin{array}{c}\text { Number } \\
\text { of cases in } \\
\text { Ukraine } \\
V_{j}\end{array}$ & $\begin{array}{l}\text { Day in November } \\
\text { and December } 2020\end{array}$ & $\begin{array}{c}\text { Time } \\
\text { in days } \\
t_{j}\end{array}$ & $\begin{array}{c}\text { Number } \\
\text { of cases in } \\
\text { Ukraine } \\
V_{j}\end{array}$ \\
\hline 1 & 225 & 125798 & 8 & 262 & 250538 & 14 & 299 & 535857 \\
\hline 2 & 226 & 128228 & 9 & 263 & 256266 & 15 & 300 & 545689 \\
\hline 3 & 227 & 130951 & 10 & 264 & 261034 & 16 & 301 & 557657 \\
\hline 4 & 228 & 133787 & 11 & 265 & 265454 & 17 & 302 & 570153 \\
\hline 5 & 229 & 135894 & 12 & 266 & 270587 & 18 & 303 & 583510 \\
\hline 6 & 230 & 138068 & 13 & 267 & 276177 & 19 & 304 & 598085 \\
\hline 7 & 231 & 140479 & 14 & 268 & 281239 & 20 & 305 & 612665 \\
\hline 8 & 232 & 143030 & 15 & 269 & 287231 & 21 & 306 & 624744 \\
\hline 9 & 233 & 145612 & 16 & 270 & 293641 & 22 & 307 & 635689 \\
\hline 10 & 234 & 148756 & 17 & 271 & 298872 & 23 & 308 & 647976 \\
\hline 11 & 235 & 151859 & 18 & 272 & 303638 & 24 & 309 & 661858 \\
\hline 12 & 236 & 154335 & 19 & 273 & 309107 & 25 & 310 & 677189 \\
\hline 13 & 237 & 156797 & 20 & 274 & 315826 & 26 & 311 & 693407 \\
\hline 14 & 238 & 159702 & 21 & 275 & 322879 & 27 & 312 & 709701 \\
\hline 15 & 239 & 162660 & 22 & 276 & 330396 & 28 & 313 & 722679 \\
\hline 16 & 240 & 166244 & 23 & 277 & 337410 & 29 & 314 & 732625 \\
\hline 17 & 241 & 169472 & 24 & 278 & 343498 & 30 & 315 & 745123 \\
\hline 18 & 242 & 172712 & 25 & 279 & 348924 & 1 & 316 & 758264 \\
\hline 19 & 243 & 175678 & 26 & 280 & 355601 & 2 & 317 & 772760 \\
\hline 20 & 244 & 178353 & 27 & 281 & 363075 & 3 & 318 & 787891 \\
\hline 21 & 245 & 181237 & 28 & 282 & 370417 & 4 & 319 & 801716 \\
\hline 22 & 246 & 184734 & 29 & 283 & 378729 & 5 & 320 & 813306 \\
\hline 23 & 247 & 188106 & 30 & 284 & 387481 & 6 & 321 & 821947 \\
\hline 24 & 248 & 191671 & 31 & 285 & 395440 & 7 & 322 & 832758 \\
\hline 25 & 249 & 195504 & 1 & 286 & 402194 & 8 & 323 & 845343 \\
\hline 26 & 250 & 198634 & 2 & 287 & 411093 & 9 & 324 & 858714 \\
\hline 27 & 251 & 201305 & 3 & 288 & 420617 & 10 & 325 & 872228 \\
\hline 28 & 252 & 204932 & 4 & 289 & 430467 & 11 & 326 & 885039 \\
\hline 29 & 253 & 208959 & 5 & 290 & 440188 & 12 & 327 & 894215 \\
\hline 30 & 254 & 213028 & 6 & 291 & 450934 & 13 & 328 & 900666 \\
\hline 1 & 255 & 217661 & 7 & 292 & 460331 & 14 & 329 & 909082 \\
\hline 2 & 256 & 222322 & 8 & 293 & 469018 & 15 & 330 & 919704 \\
\hline 3 & 257 & 226462 & 9 & 294 & 479197 & 16 & 331 & 931751 \\
\hline 4 & 258 & 230236 & 10 & 295 & 489808 & 17 & 332 & 944381 \\
\hline 5 & 259 & 234584 & 11 & 296 & 500865 & 18 & 333 & 956123 \\
\hline 6 & 260 & 239337 & 12 & 297 & 512652 & 19 & 334 & 964448 \\
\hline 7 & 261 & 244734 & 13 & 298 & 525176 & 20 & 335 & 970993 \\
\hline
\end{tabular}


Table 3: Cumulative numbers of confirmed Covid-19 cases in Ukraine in winter 2020-2021: $V_{j 1}$-National statistics (UNS), [2, 3] and $V_{j 2}$ - according to COVID-19 Data Repository by the Center for Systems Science and Engineering (CSSE) at Johns Hopkins University (JHU), [4].

\begin{tabular}{|c|c|c|c|c|c|}
\hline $\begin{array}{l}\text { Day in } \\
\text { December } \\
2020\end{array}$ & $\begin{array}{c}\text { Number } \\
\text { of cases, } \\
\text { UNS, [2, 3] } \\
V_{j 1}\end{array}$ & $\begin{array}{c}\text { Number } \\
\text { of cases, } \\
\text { JHU, [4] } \\
V_{j 2}\end{array}$ & $\begin{array}{c}\text { Day in } \\
\text { January } \\
2021\end{array}$ & $\begin{array}{c}\text { Number } \\
\text { of cases, } \\
\text { UNS, [2, 3] } \\
V_{j 1}\end{array}$ & $\begin{array}{c}\text { Number } \\
\text { of cases, } \\
\text { JHU, [4] } \\
V_{j 2}\end{array}$ \\
\hline 1 & 758264 & 765117 & 1 & 1069517 & 1096855 \\
\hline 2 & 772760 & 778560 & 2 & 1074093 & 1102256 \\
\hline 3 & 787891 & 793372 & 3 & 1078251 & 1107137 \\
\hline 4 & 801716 & 808828 & 4 & 1083585 & 1111631 \\
\hline 5 & 813306 & 822985 & 5 & 1090496 & 1117256 \\
\hline 6 & 821947 & 834913 & 6 & 1099493 & 1124482 \\
\hline 7 & 832758 & 843898 & 7 & 1105169 & 1133802 \\
\hline 8 & 845343 & 855054 & 8 & 1110015 & 1139800 \\
\hline 9 & 858714 & 867991 & 9 & 1115026 & 1144943 \\
\hline 10 & 872228 & 881727 & 10 & 1119314 & 1150265 \\
\hline 11 & 885039 & 895620 & 11 & 1124430 & 1154850 \\
\hline 12 & 894215 & 908839 & 12 & 1130839 & 1160243 \\
\hline 13 & 900666 & 918444 & 13 & 1138764 & 1166958 \\
\hline 14 & 909082 & 925321 & 14 & 1146963 & 1175343 \\
\hline 15 & 919704 & 934161 & 15 & 1154692 & 1183963 \\
\hline 16 & 931751 & 945218 & 16 & 1160682 & 1192114 \\
\hline 17 & 944381 & 957692 & 17 & 1163716 & 1198512 \\
\hline 18 & 956123 & 970758 & 18 & 1167655 & 1201894 \\
\hline 19 & 964448 & 982937 & 19 & 1172038 & 1206125 \\
\hline 20 & 970993 & 991700 & 20 & 1177621 & 1210854 \\
\hline 21 & 979506 & 998678 & 21 & 1182969 & 1216780 \\
\hline 22 & 989642 & 1007627 & 22 & 1187897 & 1222459 \\
\hline 23 & 1001132 & 1018199 & 23 & 1191812 & 1227723 \\
\hline 24 & 1012167 & 1030125 & 24 & 1194328 & 1231965 \\
\hline 25 & 1019876 & 1041583 & 25 & 1197107 & 1234772 \\
\hline 26 & 1025989 & 1049717 & 26 & 1200883 & 1237810 \\
\hline 27 & 1030374 & 1056265 & 27 & 1206412 & 1241863 \\
\hline 28 & 1037362 & 1061074 & 28 & 1211593 & 1247674 \\
\hline 29 & 1045348 & 1068476 & 29 & 1216278 & 1253127 \\
\hline 30 & 1055047 & 1076880 & 30 & 1219455 & 1258093 \\
\hline 31 & 1064479 & 1086997 & 31 & 1221485 & 1261546 \\
\hline
\end{tabular}

spread the infection; please don't confuse with the number of still ill persons, so known active cases) and the number of removed $R$ (persons who no longer spread the infection; this number is the sum of isolated, recovered, dead, and infected people who left the region):

$$
\begin{gathered}
\frac{d S}{d t}=-\alpha_{i} S I \\
\frac{d I}{d t}=\alpha_{i} S I-\rho_{i} I,
\end{gathered}
$$




$$
\frac{d R}{d t}=\rho_{i} I
$$

Parameters $\alpha_{i}$ and $\rho_{i}$ are supposed to be constant for every wave of the epidemics, i.e. for the time periods $t_{i}^{\star} \leq t \leq t_{i+1}^{\star}, i=1,2,3, \ldots$

Parameters $\alpha_{i}$ show how quick the susceptible persons become infected (see (4)). Large values of this parameter correspond to severe epidemics with many victims. These parameters accumulate many characteristics. First they show how strong (virulent) is the pathogen and what is the way of its spreading. Parameters $\alpha_{i}$ accumulate also the frequency of contacts and the way of contacting. In order to decrease the values of $\alpha_{i}$, we have to minimize the number of our contacts and change our contacting habits. For example, we have to avoid the public places and use masks there, minimize or cancel traveling. We have to change our contact habits: to avoid handshakes and kisses. First, all these simple things are very useful to protect yourself. In addition, if most people follow these recommendations, we have chance to diminish the values of parameter $\alpha_{i}$ and reduce the negative effects of the pandemic.

The parameters $\rho_{i}$ characterize the patient removal rates, since eq. (6) demonstrates the increase rate for $R$. The inverse values $1 / \rho_{i}$ are the estimations for time of spreading the infection $\tau$. So, we are interested in increasing the values of parameters $\rho_{i}$ and decreasing $1 / \rho_{i}$. People and public authorities should work on this and organize immediate isolation of suspicious cases.

Since the derivative $d(S+I+R) / d t$ is equal to zero (it follows from summarizing Eqs. (4)-(6)), the sum

$$
N_{i}=S+I+R
$$

must be constant for every wave and is not the volume of population (see also [20]).

\subsection{Analytical solution of SIR equations}

To determine the initial conditions for the set of equations (4)-(6), let us suppose that at the beginning of every epidemic wave $t_{i}^{*}$ :

$$
I\left(t_{i}^{*}\right)=I_{i}, \quad R\left(t_{i}^{*}\right)=R_{i}, \quad S\left(t_{i}^{*}\right)=N_{i}-I_{i}-R_{i}
$$

In particular, when the first wave of the epidemic starts with one infected person, the initial conditions (8) can be written as follows:

$$
I\left(t_{1}^{*}\right)=1, \quad R\left(t_{1}^{*}\right)=0, \quad S\left(t_{1}^{*}\right)=N_{1}-1 .
$$

Equations (9) were used in $[9,10,11,12,13,14,15,16,17,18,19,20]$ to simulate the first waves of the COVID-19 pandemic in different countries.

It follows from (4) and (5) that

$$
\frac{d I}{d S}=\frac{v_{i}}{S}-1, v_{i}=\frac{\rho_{i}}{\alpha_{i}}
$$

Integration of (10) with the initial conditions (8) yields:

$$
I=v_{i} \ln S-S+N_{i}-R_{i}-v_{i} \ln \left(N_{i}-I_{i}-R_{i}\right)
$$

It follows from (11) that function $I$ has a maximum at $S=v_{i}$ and tends to zero at infinity. The corresponding number of susceptible persons at infinity $S_{i \infty}>0$ can be calculated from a non-linear equation

$$
S_{i \infty}=\left(N_{i}-I_{i}-R_{i}\right) e^{\frac{S_{i \infty}-N_{i}-R_{i}}{v}}
$$

Formula (12) follows from (11) at $I=0$.

As in [8] we solve (4)-(6) by introducing the function $V(t)=I(t)+R(t)$, corresponding to the number of victims or cumulative confirmed number of cases. It follows from (5)-(7) and (11) that:

$$
\frac{d V}{d t}=\alpha_{i} S I=\alpha_{i}\left(N_{i}-V\right)\left[v_{i} \ln \left(N_{i}-V\right)+V-R_{i}-v_{i} \ln \left(N_{i}-R_{i}-I_{i}\right)\right]
$$


Integration of (13) yield an analytical solution for the set of equations (4)-(6):

$$
\begin{gathered}
F_{i}^{*}\left(V, N_{i}, I_{i}, R_{i}, v_{i}\right)=\alpha_{i}\left(t-t_{i}^{*}\right), \\
F_{i}^{*}=\int_{R_{i}+I_{i}}^{V} \frac{d U}{(N-U)\left[v_{i} \ln \left(N_{i}-U\right)+U-R_{i}-v_{i} \ln \left(N_{i}-R_{i}-I_{i}\right)\right]} .
\end{gathered}
$$

Thus, for every set of parameters $N_{i}, I_{i}, R_{i}, v_{i}, \alpha_{i}, t_{i}^{*}$ and a fixed value of $V$, integral (15) can be calculated and a corresponding moment of time can be determined from (14). Then functions $I(t)$ and $R(t)$ can be easily calculated with the use of formulas (11) and:

$$
S=N_{i}-V, R=V-I
$$

The final number of victims (final accumulated number of cases in $i$-th epidemic wave) can be calculated from:

$$
V_{i \infty}=N_{i}-S_{i \infty} .
$$

To estimate the final day of an epidemic wave, we can use the condition:

$$
I\left(t_{i f}\right)=1 .
$$

which means that at $t>t_{\text {if }}$ less than one person still spreads the infection.

\subsection{Parameter identification procedures}

In the case of a new epidemic, the values of its independent six parameters are unknown and must be identified with the use of limited data sets. For the first wave of an epidemic starting with one infected person, the number of unknown parameters is only four, since $I_{1}=1$ and $R_{1}=0$. The corresponding statistical approach was used in $[8,9,10,11,12,13,14,15,16,17,18,19,20]$ to estimate the values of four unknown parameters.

For the next epidemic waves $(i>1)$, the moments of time $t_{i}^{\star}$ corresponding to their beginning are known. Therefore the exact solution (14)-(16) depend only on five parameters $-N_{i}, I_{i}, R_{i}, v_{i}, \alpha_{i}$. Then the registered number of victims $V_{j}$ corresponding to the moments of time $t_{j}$ can be used in eq. (15) in order to calculate $F_{i, j}=F_{i}^{\star}\left(V_{j}, N_{i}, v_{i}, I_{i}, R_{i}\right)$ for every fixed values of $N_{i}, v_{i}, I_{i}, R_{i}$ and then to check how the registered points fit the straight line (14).

Eq. (14) can be rewritten as follows:

$$
y \equiv F_{i}^{\star}\left(V, N_{i}, I_{i}, R_{i}, v_{i}\right)=\gamma t+\beta, \quad \gamma=\alpha_{i}, \quad \beta=-\alpha_{i} t_{i}^{\star}
$$

We can estimate the values of parameters $\gamma$ and $\beta$, by treating the values $y_{j} \equiv F_{i}^{\star}\left(V_{i}, N_{i}, I_{i}, R_{i}, v_{i}\right)$ and corresponding time moments $t_{j}$ as random variables. Then we can use the observations of the accumulated number of cases and the linear regression in order to calculate the coefficients $\widehat{\gamma}$ and $\widehat{\beta}$ of the regression line

$$
\widehat{y}=\widehat{\gamma} t+\widehat{\beta}
$$

using the standard formulas from, e.g., [25]. Values $\widehat{\gamma}$ and $\widehat{\beta}$ can be treated as statistics-based estimations of parameters $\gamma$ and $\beta$ from relationships (19).

The reliability of the method can be checked by calculating the correlation coefficients $r_{i}$ (see e.g., [25]) for every epidemic wave checking how close is its value to unity. We can use also the F-test for the null hypothesis that says that the proposed linear relationship (19) fits the data set. The experimental values of the Fisher function can be calculated for every epidemic wave with the use of the formula:

$$
F_{i}=\frac{r_{i}^{2}\left(n_{i}-m\right)}{\left(1-r_{i}^{2}\right)(m-1)}
$$


where $n_{i}$ is the number of observations for the $i$-th epidemic wave, $m=2$ is the number of parameters in the regression equation. The corresponding experimental value $F_{i}$ has to be compared with the critical value $F_{C}\left(k_{1}, k_{2}\right)$ of the Fisher function at a desired significance or confidence level $\left(k_{1}=m-1, k_{2}=n_{i}-m\right)$. When the values $n_{i}$ and $m$ are fixed, the maximum of the Fisher function coincides with the maximum of the correlation coefficient. Therefore, to find the optimal values of parameters $N_{i}, v_{i}, I_{i}, R_{i}$, we have to find the maximum of the correlation coefficient for the linear dependence (19). To compare the reliability of different predictions (with different values of $n_{i}$ ) it is useful to use the ratio $F_{i} / F_{C}\left(1, n_{i}-2\right)$ at fixed significance level. We will use the level 0.001; corresponding values of $F_{C}\left(1, n_{i}-2\right)$ can be taken from [26]. The most reliable prediction yields the highest $F_{i} / F_{C}\left(1, n_{i}-2\right)$ ratio.

The exact solution (14)-(16) allows avoiding numerical solutions of differential equations (4)-(6) and significantly reduce the time spent on calculations. In the case of sequential calculation of epidemic waves $i=$ $1,2,3 \ldots$, it is possible to avoid determining the four optimal unknown parameters $N_{i}, v_{i}, I_{i}, R_{i}$, thereby reducing the amount of calculations and difficulties in isolation a maximum of the correlation coefficient. For parameters $I_{i}, R_{i}$ it is possible to use the numbers of $I$ and $R$ calculated for the previous wave of epidemic at the moment of time when the following wave began. Then we need to calculate values $F_{i}^{\star}\left(V_{i}, N_{i}, v_{i}\right)$, linear regression coefficients in (20), correlation coefficient $r_{i}, F_{i} / F_{C}(1, n-2)$ and to isolate the values of parameters $N_{i}$ and $v_{i}$ corresponding to the maximum of $r_{i}$. Knowing the optimal values of five parameters $N_{i}, I_{i}, R_{i}, v_{i}, \alpha_{i}$, the SIR curves and other characteristics of the corresponding epidemic wave can be calculated with the use of formulas (10)-(18). This approach has been successfully used in [20]. In particular, six waves of the Covid-19 epidemic in Ukraine and four pandemic waves in the world were calculated.

Segmentation of epidemic waves and their sequential SIR simulations need a lot of efforts. To avoid this, a new method of obtaining the optimal values of SIR parameters was proposed in [20]. First of all we can use the relationship

$$
V_{i}=I_{i}+R_{i}
$$

To estimate the value $V_{i}$, we can use the smoothed accumulated number of cases (e.g., formula (1)). Then

$$
V_{i} \approx \frac{1}{7} \sum_{j=i-3}^{j=i+3} V_{j}
$$

where $i$ corresponds to the moment of time $t_{i}^{\star}$. To obtain one more relationship, let us use (5)- (7). Then

$$
I_{i}=\left.\frac{1}{\alpha_{i}\left(N_{i}-V_{i}\right)} \frac{d V}{d t}\right|_{t=t_{i}^{*}}
$$

To estimate the average number of new cases $d V / d t$ at the moment of time $t_{i}^{\star}$, we can use (2). Thus we have only two independent parameters $N_{i}$ and $v_{i}$. To calculate the value of parameter $\alpha_{i}$, some iterations can be used (see details in [20]). In this study we will use both methods of identification of SIR model parameters.

\section{Results and Discussion}

\subsection{Detection of the COVID-19 pandemic waves in Ukraine}

Applications of formulae (1)-(3) for the pandemic dynamics in Ukraine are shown in Figs. 1 and 2. The accumulated numbers of cases ("circles") were smoothed with the use of eq. (1) and shown by lines. "Triangles" and "stars" represent the results of differentiation (2) and (3) respectively. The make the results more visible, the first derivative (2) is multiplied by 100, the second one (formula (3)) - by 1000.

Fig. 1 demonstrates that the second derivatives increase after epidemic outbreak, then become smaller and negative. Such behavior is typical for the first wave of the epidemics (before May 17, 2020). The jumps in the values of the second derivative indicate changes in the conditions of the pandemic (for example, the 


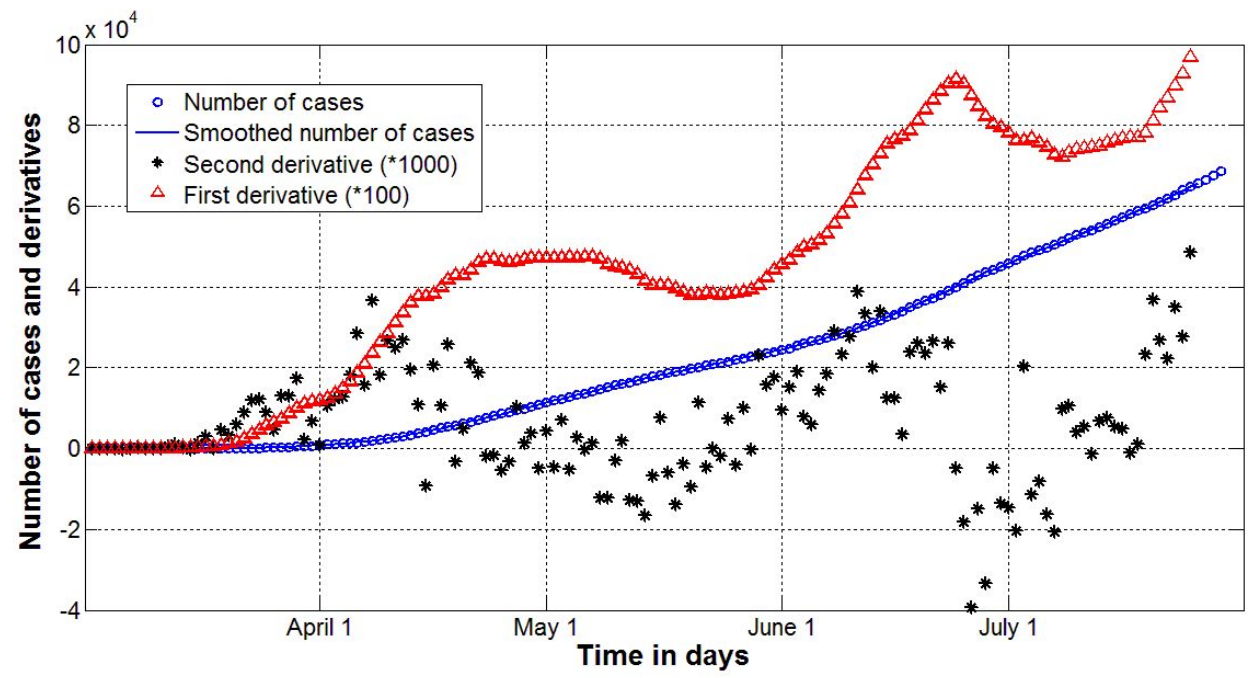

Figure 1: Epidemic dynamics in Ukraine in spring and summer 2020. Accumulated number of cases (blue markers and line, eq. (1)). Red markers represent first derivative (eq. (2)), black one show the second derivative (eq. (3)).

weakening of quarantine) and the transitions to the next waves with other values of the parameters of mathematical models. These jumps occurred on May 16, May 29, June 8, July 3 and July 19-20 (see Fig. 1). Therefore these days can be treated as the beginning of the second, third etc. waves.

The second epidemic wave in Ukraine was caused by the cancelation of the national lockdown on May 10. After the incubation period (approximately after May 16), the number of new cases began to grow faster. Further waves of the epidemic in Ukraine are associated with further easing of quarantine and mass noncompliance with social distancing. The fifth epidemic wave in Ukraine can be explained by the consequences of the holiday season, which increased the number of trips and violations of social distancing.

The COVID-19 pandemic characteristics for Ukraine in autumn 2020 are shown in Fig. 2. Differentiation of the smoothed number of accumulated cases (eq. (1), line) with the use of formulas (2) ("triangles") and (3) (stars) allow us to detect the changes in epidemic dynamics. It can be seen that after November 25 the average daily number of new cases ("triangles") started to decrease. Similar short periods of the epidemic stabilization occurred in May, June and August, 2020 (see Fig. 1).

The values of the second derivative (3) allow detecting the changes in the epidemic characteristics and separating its different waves. The jump in $d^{2} V / d t^{2}$ values corresponding to September 11 (see "stars" in Fig. 2) can be explained by the beginning of classes in schools and universities (on September 1). Children and young people are often asymptomatic carriers of the infection and bring it to their families. For example, employees of two kindergartens and two schools in the Ukrainian city of Chmelnytskii were tested for antibodies to COVID-19, [27]. In total 292 people work in the surveyed institutions. Some of the staff had already fallen ill with COVID-19 or were hospitalized. Therefore, they were not tested accordingly. Of the 241 educators tested, antibodies were detected in 148 , or $61.4 \%$. These results indicate the important role of children in the spread of COVID-19 infection and the fact that in Ukraine those people who have become ill and have antibodies to coronavirus infection, obviously, are much more than the official statistics (presented in Tables 1-3) states.

The severe jumps in $d^{2} V / d t^{2}$ values occurred also in October and November, 2020 (see "stars" in Fig. 2). Probably, this is due to the local elections and a presidential poll, which were held throughout Ukraine on October 25, 2020 and involved hundreds of thousands of people to campaign and work in election commissions (their number was about 30 thousand). This obviously increased the number of contacts and the likelihood of additional infections. The corresponding seventh epidemic wave in Ukraine was considered in [20].

In November 2020, the Ukrainian government introduced a weekend lockdown. In the period from 00:00 on Saturday to 00:00 on Monday in Ukraine from November 14 to November 30 it was prohibited: the work of catering establishments (except for takeaway services), the work of shopping and entertainment centers, 


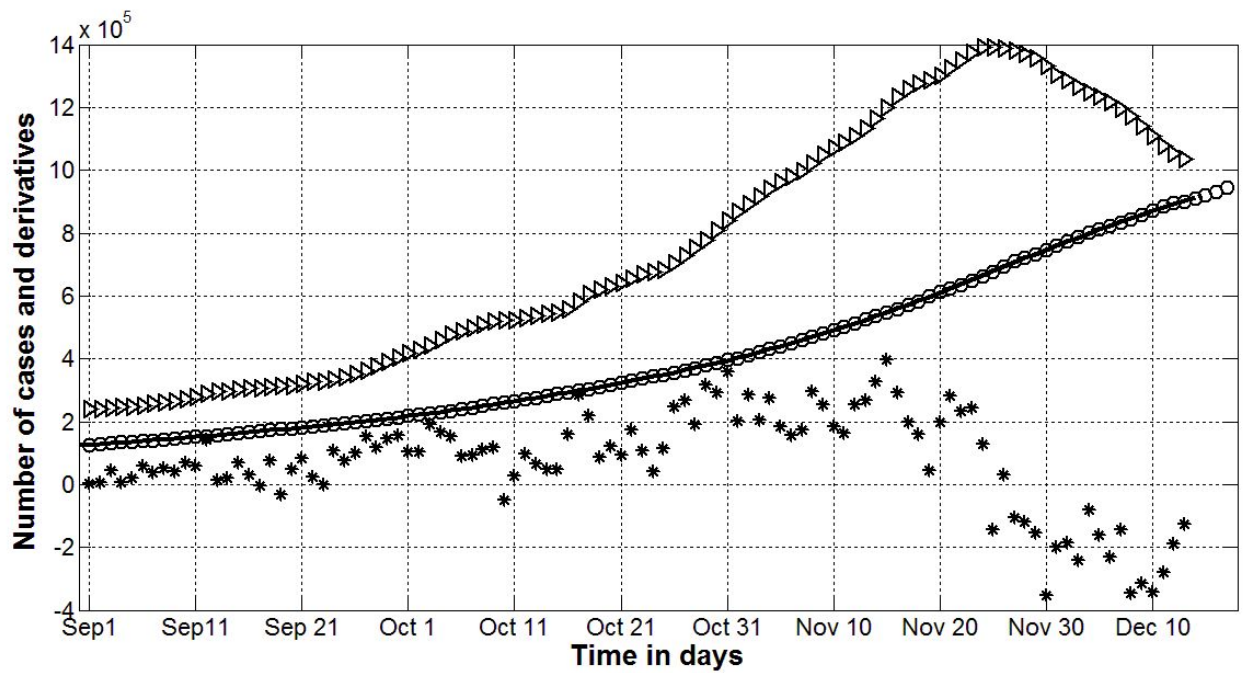

Figure 2: Pandemic dynamics in Ukraine in autumn, 2020. Accumulated number of cases ( $V_{j}$ - "cicrles", Table 2 and 3; smoothed values - line, eq. (1)). "Triangles" show the first derivative (eq. (2)) multiplied by 100, "stars" - the second derivative (eq. (3)) multiplied by 1000 .

entertainment establishments, the activities of economic entities engaged in trade and consumer services, except for food trade in retail space, at least 60 percent of which intended for trade in food, fuel, medicines and medical devices, veterinary drugs, feed. It was prohibited to operate cultural institutions and hold cultural events. Gyms, fitness centers and swimming pools should also be closed, [28]. Probably, positive results of this lockdown are visible in Fig. 2. Between November 21 and December 10 (after some incubation period) we can see decreasing of the second derivative ("stars").

The SIR simulations of corresponding epidemic waves in Ukraine will be presented in the next Section. In some cases the distance between jumps of the second derivative was too small to make statistical estimates of the parameters (e.g., in the second half of May 2020), so the individual waves of the epidemic during these periods were not isolated.

The COVID-19 pandemic characteristics for Ukraine in December 2020 and January 2021 are shown in Figs. 3 and 4. Red color corresponds to the national statistics (UNS) [2, 3]; black - to JHU data [4]. "Circles" show the corresponding accumulated numbers of cases; lines represent the smoothed number of accumulated cases (eq. (1) ); "crosses" - the first derivative (eq. (2)) multiplied by 10; "dots" - second derivative (eq. (3)) multiplied by 1000. Fig. 3 illustrates the data sets presented in Table 3. It can be seen one day shift for the values of the second derivatives calculated with the use of different data sets. If the numbers of cases reported by JHU are attributed to the previous day, the differences in the values of the second derivatives become almost imperceptible (see Fig. 4), but the numbers of accumulated cases according to JHU are still much higher than for UNS (see Fig. 4).

The jump of the second derivatives occurred on January 10-12, 2021 (see "dots" in Fig. 4) can be explained the New Year and Christmas celebrations. The increase in the number of contacts caused the increase in the number of new cases after some incubation period (see "crosses" in Figs. 3 and 4). The national lockdown in the period January 8-24, 2021 allowed stopping this tendency.

\subsection{Results of SIR simulations}

The first epidemic wave in Ukraine were already simulated with the use of classical SIR model $[14,15,16,17$, $18,19,20]$. Usually the number of cases during the initial period of a new epidemic outbreak is not reliable, since many cases are not detected. That is why the first waves need re-estimations after obtaining fresh data. 


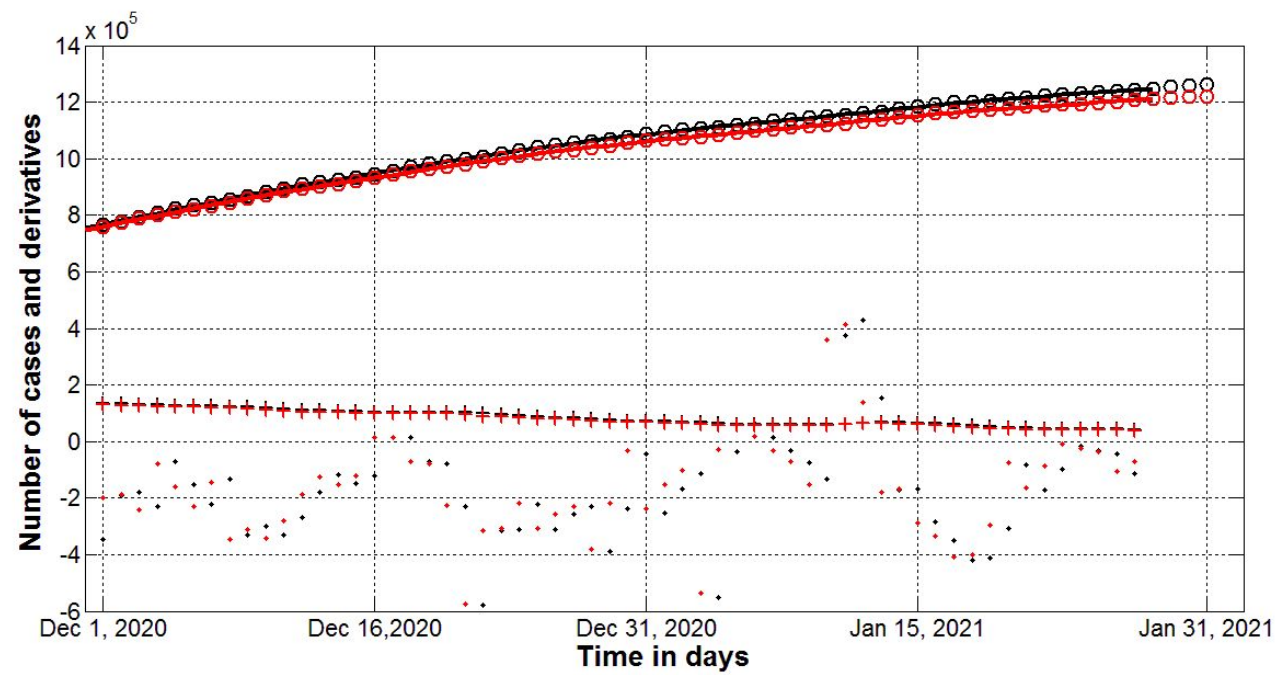

Figure 3: Pandemic dynamics in Ukraine in December 2020 and January 2021 calculated with the use of data sets from Table 3: UNS [2, 3] (red) and data set reported by JHU [4] (black). Accumulated number of cases - "circles"; smoothed values - lines, eq. (1)). "Crosses" show the first derivatives (eq. (2)) multiplied by 10, "dots" - the second derivative (eq. (3) ) multiplied by 1000.

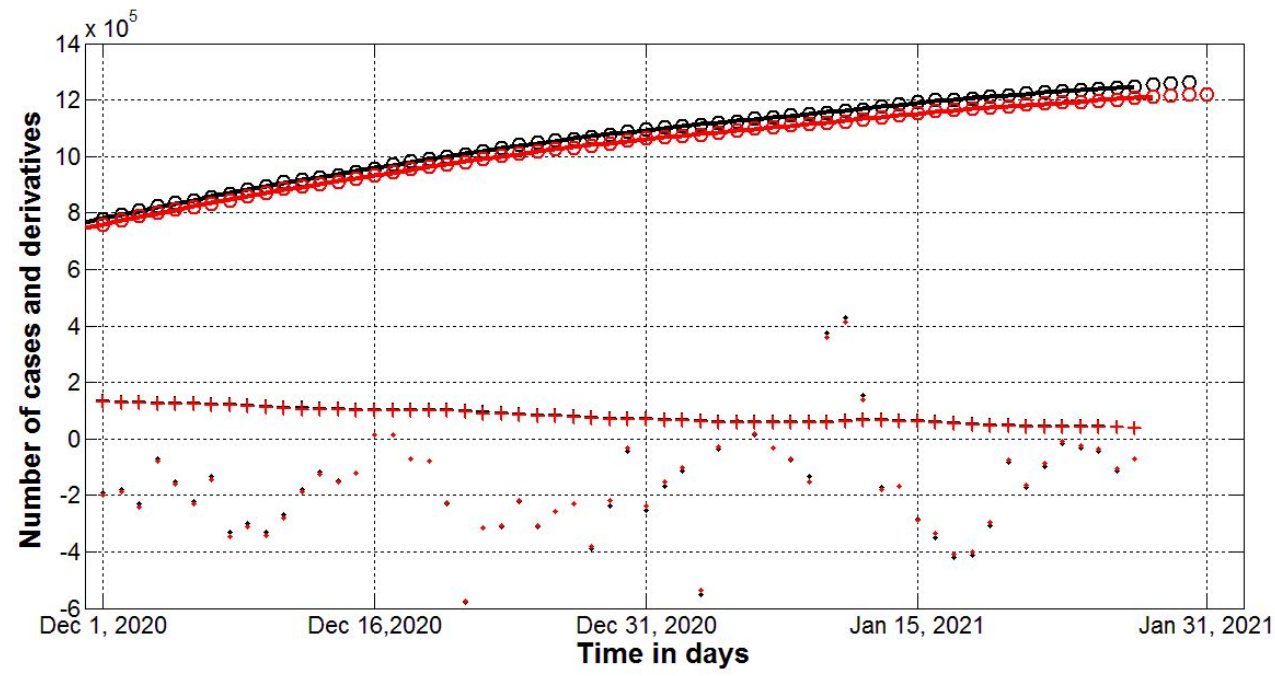

Figure 4: Pandemic dynamics in Ukraine in December 2020 and January 2021 with the numbers of cases reported by JHU attributed to the previous day: UNS [2,3] (red) and data set reported by JHU [4] (black). Accumulated number of cases - "circles"; smoothed values - lines, eq. (1)). "Crosses" show the first derivatives (eq. (2)) multiplied by 10, "dots" - the second derivative (eq. (3) ) multiplied by 1000 .

To illustrate the influence of data on the results of SIR simulations, different estimations of the first epidemic wave in Ukraine are presented in Table 4. It can be seen, that the use of more recent (and complete) data has changed the estimation for the pandemic beginning. Table 4 illustrates that prediction 21 calculated with the use of number of cases from the period May 3-16 (immediately before the start of the second wave) yields much longer hidden period of the epidemic outbreak in Ukraine in comparison with the previous prediction 8, [16]. Prediction 19, [19] yields even longer hidden period, but it was obtained with the use of the dataset for the period May 13-26, which corresponds the transition form first to the second wave. This prediction yielded the smallest values of $F_{i}$ and $F_{i} / F_{C}\left(1, n_{i}-2\right)$ in comparison with predictions 8 and 21 (see Table 4). The maximum corresponding values of these parameters demonstrate that the prediction 21 estimating the epidemic outbreak in Ukraine in the beginning of January, 2020 is probably the most reliable. Similar 
Table 4: Characteristics of the first epidemic wave in Ukraine calculated with the use of different data sets. Optimal values of parameters, final sizes and days (last three rows).

\begin{tabular}{|c|c|c|c|}
\hline Characteristics & $\begin{array}{c}\text { Ukraine, } \\
\text { first wave, } \\
\text { prediction } 8,[16] \\
i=1\end{array}$ & $\begin{array}{c}\text { Ukraine, } \\
\text { first wave, } \\
\text { prediction 19, [19] } \\
\text { i=1 }\end{array}$ & $\begin{array}{c}\text { Ukraine, } \\
\text { first wave, } \\
\text { prediction } 21,[20] \\
i=1\end{array}$ \\
\hline $\begin{array}{l}\text { Period taken for } \\
\text { calculations }\end{array}$ & April 11-24 & May 13-26 & May 3-16 \\
\hline$I_{i}$ & 1 & 1 & 1 \\
\hline$R_{i}$ & 0 & 0 & 0 \\
\hline$N_{i}$ & 21380.9241600000 & 92770.3987200000 & 59002.368 \\
\hline$v_{i}$ & 12190.2413389748 & 76647.6354922344 & 43307.0168670536 \\
\hline$\alpha_{i}$ & $1.45792603472 \mathrm{e}-05$ & 3.766268949867e-06 & 4.62451395337e-06 \\
\hline$t_{i}$ & 27.72672361552338 & -32.4672286400970 & -16.5560950369874 \\
\hline$\rho_{i}$ & 0.177724702176649 & 0.288675609635095 & 0.200273903780639 \\
\hline $1 / \rho_{i}$ & 5.62667984671 & 3.46409591466375 & 4.99316177056849 \\
\hline$r_{i}$ & 0.998863416866565 & 0.998856483326519 & 0.999453409358706 \\
\hline$F_{i}$, eq. (21) & 5269.98203160936 & 5237.97374486281 & 10968.1371753815 \\
\hline$F_{i} / F_{C}\left(1, n_{i}-2\right)$ & 283.332367290826 & 281.611491659291 & 589.684794375351 \\
\hline$S_{i \infty}$, eq. (12) & 6108 & 62507 & 30676 \\
\hline$V_{i \infty}$, eq. (17) & 15273 & 30263 & 28327 \\
\hline$t_{i f}$, eq. (18) & 186.5 & 273.6 & 264.9 \\
\hline $\begin{array}{l}\text { Final day of } \\
\text { epidemic }\end{array}$ & July 26, 2020 & October 20, 2020 & October 11, 2020 \\
\hline
\end{tabular}

simulations of the global dynamics show that the COVID-19 pandemic probably started in the beginning of August 2019, [20].

The characteristics of the pandemic waves 2-4 for Ukraine are presented in Table 5. The results of SIR simulations of the next pandemic waves in Ukraine are shown in Tables 6 and 7 and in Figs. 5-7. In can be seen that optimal values of the model parameters are rather different for different pandemic waves. In particular, the final sizes and durations of the pandemic significantly differ. It is not surprising, since different time periods $T_{c i}$ with different conditions were used for calculations. Value $n_{i}=14$ and general SIR model were used for all the cases. The periods $T_{c i}$ taken for calculations were selected according to the time periods of the corresponding epidemic waves (see Tables 5-7).

Fig. 5 illustrates first six epidemic waves in Ukraine. The accumulated number of cases $V=I+R$ (solid lines) increases for each next wave. Every new wave also increases the number of infected and spreading the infection persons $I$. The calculated dependences $10^{*} I(t)$ are shown by dashed lines. The accuracy of simulations is rather good, especially for second and further waves of pandemic, since blue "stars" ( showing the accumulated values of confirmed cases used only for control the calculations) are located very close to the corresponding solid lines showing the calculated $V=I+R$ values. There are some discrepancies for the early stages of first waves, when the number of registered cases is lower that the real one due to the problems with the identification of the infected persons.

Fig. 6 illustrates rather good accuracy of SIR simulations. In particular, the $V_{j}$ values ("triangles") started to deviate from the solid red line only after September 16 . This fact can be explained by the beginning classes in schools and universities (as mentioned above). This curve was calculated with the use of data set from the period August 9-22. The increased number of contacts in schools and universities caused rapid increase of the number of cases. This increase in the number of diseases intensified in October and November 2020 through elections and a presidential poll. The very irregular nature of the epidemic dynamics (particularly the large values of the second derivative (see "stars" in Fig. 1)) led to the fact that $V=I+R$ curve for the seventh wave 
Table 5: Characteristics of second, third and fourth epidemic waves in Ukraine. Optimal values of parameters, final sizes and days (last three rows).

\begin{tabular}{|c|c|c|c|}
\hline Characteristics & $\begin{array}{c}\text { Ukraine, } \\
\text { second wave, } \\
\mathbf{i}=\mathbf{2}\end{array}$ & $\begin{array}{c}\text { Ukraine, } \\
\text { third wave, } \\
\boldsymbol{i}=\mathbf{3}\end{array}$ & $\begin{array}{c}\text { Ukraine, } \\
\text { fourth wave, } \\
\boldsymbol{i}=\mathbf{4}\end{array}$ \\
\hline $\begin{array}{c}\text { Period taken for } \\
\text { calculations, } T_{c i}\end{array}$ & May 17-30 & June 9-22 & July 3-16 \\
$I_{i}$ & 2196 & 2490 & 3736 \\
$R_{i}$ & 16420 & 25891 & 43941 \\
$N_{i}$ & 239587.2 & 149444.16 & 182294.495539200 \\
$v_{i}$ & 209382.9208704 & 104004.527376384 & 119723.766724183 \\
$\alpha_{i}$ & $7.728220925 \mathrm{e}-07$ & $2.117564829222 \mathrm{e}-06$ & $1.35741149806184 \mathrm{e}-06$ \\
$\rho_{i}$ & 0.161815747046830 & 0.220236329252125 & 0.162514417542680 \\
$1 / \rho_{i}$ & 6.179868826529682 & 4.54057694929708 & 6.15330021250195 \\
$r_{i}$ & 0.998894780369877 & 0.999714332158213 & 0.999456710370030 \\
$F_{i}$, eq. (21) & 5419.78688520125 & 20994.4146122108 & 11034.8339181942 \\
$F_{i} / F_{C}\left(1, n_{i}-2\right)$ & 291.386391677487 & 1128.73196839843 & 593.270640763128 \\
$S_{i \infty}$, eq. (12) & 178641 & 78509 & 89552 \\
$V_{\text {iळ }}$, eq. (17) & 60946 & 70935 & 92742 \\
$t_{i f}$, eq. (18) & 531.9 & 338.5 & 421.7 \\
Final day of & & & \\
epidemic & July 5, 2021 & December 24, 2020 & March 17, 2021 \\
\hline
\end{tabular}

Table 6: Characteristics of fifth, sixth and seventh epidemic waves in Ukraine. Optimal values of parameters, final sizes and days (last three rows).

\begin{tabular}{|c|c|c|c|}
\hline Characteristics & $\begin{array}{l}\text { Ukraine, } \\
\text { fifth wave, } \\
\mathrm{i}=5,[20]\end{array}$ & $\begin{array}{l}\text { Ukraine, } \\
\text { sixth wave, } \\
\text { i=6, [20] }\end{array}$ & $\begin{array}{c}\text { Ukraine, } \\
\text { seventh wave, } \\
\text { i=7, [20] }\end{array}$ \\
\hline $\begin{array}{l}\text { Period taken for } \\
\text { calculations, } T_{c i}\end{array}$ & July 20-Aug 2 & August 9-22 & October 1-14 \\
\hline$I_{i}$ & 4570 & 7525 & 17605.4705407746 \\
\hline$R_{i}$ & 55596 & 73424 & 200051.672316368 \\
\hline$N_{i}$ & 208624.896 & 336210.688000000 & 566602.33216 \\
\hline$v_{i}$ & 117860.44860629 & 166678.304458998 & 271873.891638209 \\
\hline$\alpha_{i}$ & $1.241234878 \mathrm{e}-06$ & $6.47063569 \mathrm{e}-07$ & $6.811436620341 \mathrm{e}-07$ \\
\hline$t_{i}^{*}$ & 182 & 201 & 255 \\
\hline$\rho_{i}$ & 0.1462924996005 & 0.107851458558717 & 0.185185178161924 \\
\hline $1 / \rho_{i}$ & 6.83562043666339 & 9.27201183334553 & 5.40000020479830 \\
\hline$r_{i}$ & 0.9997539353297 & 0.999591012582638 & 0.999637260478932 \\
\hline$F_{i}$, eq. (21) & 24374.834072843 & 14661.3785892930 & 16531.7953887678 \\
\hline$F_{i} / F_{C}\left(1, n_{i}-2\right)$ & 1310.47495015287 & 788.246160714677 & 888.806203697193 \\
\hline$S_{\text {ios }}$, eq. (12) & 79668 & 91157 & 168285 \\
\hline$V_{i \infty \infty}$, eq. (17) & 128957 & 245054 & 398317 \\
\hline$t_{\text {if }}$, eq. (18) & 381 & 443.5 & 432 \\
\hline $\begin{array}{l}\text { Final day of } \\
\text { epidemic }\end{array}$ & February 5, 2021 & April 8, 2021 & March 27, 2021 \\
\hline
\end{tabular}






Figure 5: Six epidemic waves in Ukraine. SIR curves (lines) and accumulated number of cases (markers) versus time. Red, black, blue, magenta, green, and brown colors correspond to waves 1, 2, 3, 4, 5, and 6 respectively. Numbers of infected and spreading $I * 10$ (dashed lines) and victims $V=I+R$ (solid lines). "Circles" represent the values $V_{j}$ taken for calculations, "stars" show the values $V_{j}$ taken for the control accuracy of simulations only.

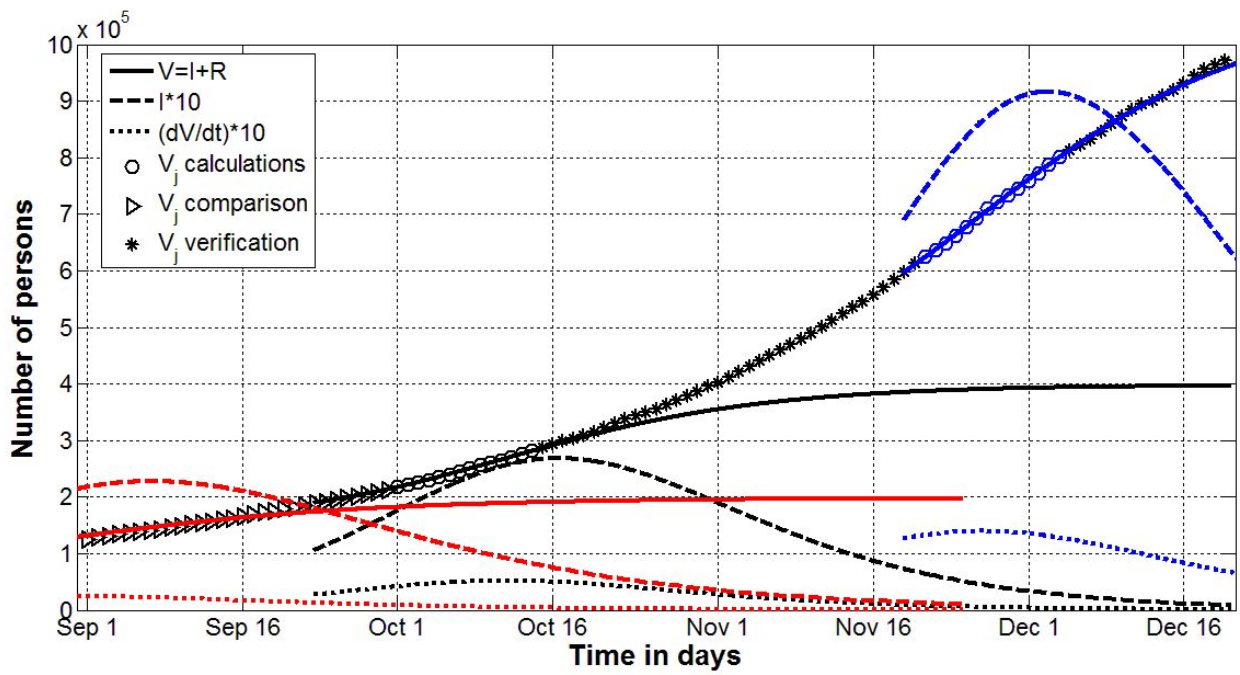

Figure 6: Sixth (red), seventh (black) and eighth (blue) COVID-19 pandemic waves in Ukraine in autumn 2020. Solid lines - the numbers of victims $V=I+R$, dashed lines - numbers of persons spreading the infection $/$ multiplied by 10 , dotted lines - the theoretical estimations of the daily numbers of new cases $d V / d t$ multiplied by 10 . The accumulated number of cases $V_{j}$ taken for calculations are shown by circles; "triangles" and "stars" correspond the cases taken only for comparisons and verifications of the predictions.

very quickly began to deviate from the recorded number of cases $V_{j}$ (compare solid black line and "stars" in Fig. 6).

The absence of sharp jumps of the second derivative after November 21, 2020 (see "stars" in Fig. 2), allowed us to predict quite accurately the further epidemic dynamics (compare solid blue line and "stars" in Fig. 6). Blue dashed line in Fig. 6 show that the number of persons spreading the infection diminished in December 2020. It can be seen that after December 16, the number of reported cases slightly exceeds the theoretical estimates (compare the blue solid line and "stars" in Fig. 6). As calculations of the eighth epidemic 
wave were carried out during the period of influence of the weekend lockdown, its cancellation probably led to increase in the number of cases.

The results of SIR simulations with the use of two data sets (UNS and JHU, presented in Table 3) are shown in Table 7 and Fig. 7. The optimal parameters of SIR model and other epidemic characteristics can be compared with the results obtained for the eighth wave (see Table 7). The number of observations taken for calculations $n_{i}$ was 14 in all the cases.

It can be seen that two data sets yield rather different values of the optimal parameters for the ninth wave (especially for $N_{9}, S_{9 \infty}$, and $v_{9}$ ), nevertheless the final sizes of this wave $V_{9 \infty}$ and $\rho_{9}$ are rather close; the duration based on the national statistics is one month longer in comparison with the calculations based on JHU data set. Both simulations for the ninth epidemic wave in Ukraine yield slightly higher final sizes in comparison with the eighth wave (see Table 7).

Table 7: Calculated optimal values of SIR parameters for the eighth and ninth waves of the COVID-19 epidemic in Ukraine

\begin{tabular}{|c|c|c|c|}
\hline Characteristics & $\begin{array}{l}\text { Eighth wave, } \\
i=8 \text {, UNS }\end{array}$ & $\begin{array}{l}\text { Ninth wave, } \\
i=9, \mathrm{JHU}, V_{j 2}\end{array}$ & $\begin{array}{l}\text { Ninth wave, } \\
i=9, \mathrm{UNS}, V_{j 1}\end{array}$ \\
\hline $\begin{array}{l}\text { Period taken for } \\
\text { calculations } T_{c i}\end{array}$ & Nov 21-Dec 4, 2020 & December 11-24, 2020 & December 11-24, 2020 \\
\hline$I_{i}$ & $74,07.6732607497$ & $62,384.6901000672$ & $59,686.0031221196$ \\
\hline$R_{i}$ & 548,996.183882108 & $830,900.452757076$ & $821,069.282592166$ \\
\hline$N_{i}$ & $1,454,508.4416$ & $1,524,200.0384$ & $2,037,235.2$ \\
\hline & 667,978.033362204 & $580,121.592967068$ & $1,141,207.02807484$ \\
\hline $\begin{array}{l}v_{i} \\
\alpha_{i}\end{array}$ & 2.138650373242e-07 & 2.91326081249e-07 & $1.55930616187218 \mathrm{e}-07$ \\
\hline$\rho_{i}$ & 0.142857147036735 & 0.169004550327192 & 0.177949115084894 \\
\hline $1 / \rho_{i}$ & 6.9999997952 & 5.91700044799982 & 5.6195840003078 \\
\hline$r_{i}$ & 0.999333327224955 & 0.998082602967150 & 0.998062592012312 \\
\hline$F_{i}$, eq. (21) & 8990.91853799112 & 3120.24523044173 & 3087.92417596763 \\
\hline$F_{i} / F_{C}\left(1, n_{i}-2\right)$ & 483.382717096297 & 167.755119916222 & 166.017428815464 \\
\hline$S_{i \infty}$, eq. (12) & 376,90 & 347,782 & 810,539 \\
\hline$V_{\text {iø }}$, eq. (17) & $1,078,218$ & $1,176,418$ & $1,226,696$ \\
\hline $\begin{array}{l}\text { Final day of the } \\
\text { epidemic wave, } \\
\text { eq. (18) }\end{array}$ & June 23, 2021 & June 15, 2021 & July 14, 2021 \\
\hline
\end{tabular}

Fig. 7 illustrates the results of SIR simulations of the ninth epidemic wave in Ukraine obtained with the use of two data sets: Ukrainian national statistics [2, 3] (red) and data set reported by JHU [4] (black). Numbers of victims $V(t)=I(t)+R(t)$ are represented by solid lines. Numbers of infected and spreading the infection persons $I(t)$ are shown by dashed lines. Dotted lines represent the derivatives $d V / d t$ calculated with the use of eq. (13). This derivative yields the estimation of the daily number of new cases. Markers show accumulated numbers of cases $V_{j 1}$ and $V_{j 2}$ from Table 3. "Circles" correspond to the accumulated numbers of cases taken for calculations (during period of time $T_{c i}$ ); “triangles" - numbers of cases before $T_{c i}$; "stars" - number of cases after $T_{c i}$. It can be seen that the accuracy of simulations based on the national statistics is rather good (the deviations between red "stars" and red solid line are small). The use of JHU data sets yields worth accuracy. Nevertheless, the real numbers of cases already exceed the predicted saturations levels for both data sets and corresponding simulations. As of February 14, 2021 the national statistics yield the figure 1,271,143 of accumulated cases in Ukraine [2, 3]. Thus the epidemic observations during 52 days (after $T_{c}$ ) demonstrated only $3.5 \%$ exceeding of the saturation level in the case of UNS. 




Figure 7: The ninth COVID-19 epidemic wave in Ukraine. SIR simulations (lines) with the use of optimal values of parameters from Table 7: national statistics [2, 3] (red) and data set reported by JHU [4] (black). Numbers of victims $V(t)=I(t)+R(t)-$ solid lines; numbers of infected and spreading $I(t)$ multiplied by 10 - dashed; derivatives $d V / d t$ (eq. (13)) multiplied by $10-$ dotted. Markers show accumulated numbers of cases $V_{j 1}$ and $V_{j 2}$ from Table 3. "Circles" correspond to the accumulated numbers of cases taken for calculations (during period of time $T_{c 9}$ ); "triangles" - numbers of cases before $T_{c 9}$; "stars" - number of cases after $T_{c 9}$.

\section{Conclusions}

Constant changes in the COVID-19 pandemic conditions (i.e., in the peculiarities of quarantine and its violation, in situations with testing and isolation of patients, in coronavirus activity due to its mutations etc.) lead to new pandemic waves and cause the changes in the values of parameters of the mathematical models. The dynamics of COVID-19 pandemic in different countries was simulated with the use of different mathematical models $[9,10,11,12,13,14,15,16,17,18,19,20,29,30,31,32,33,34,35,36,37,38,39,40,41,42,43,44,45$, $46,47,48,49,50,51,52,53,54,55,56,57,58,59,60,61,62,63,64,65,66,67,68,69,70,71,72,73,74,75$, $76,77,78,79,80,81,82,83,84,85,86,87,88,89,90,91,92,93,94]$. The results of this paper show that the accuracy of long-time predictions is limited due to these changes. Separate pandemic waves must be detected and separated in order have good accuracy of SIR models or any other simulation.

The smoothed dependence of the accumulated number of cases and its differentiation can provide fairly accurate and useful information about the course of the epidemic, identify important changes in its dynamics and provide timely recommendations for quarantine measures or control of social distancing. To simulate different pandemic waves (periods with more or less constant values of its dynamics parameters), the generalized SIR model and presented procedures of its parameters identification can be applied to calculate different pandemic waves.

Incomplete data and different methods of cases recording can give quite different values of model parameters and forecasts, which was demonstrated by the example of two data sets for Ukraine. The forecast of the duration of the epidemic in Ukraine is not optimistic. New cases will appear at least until July 2021. Let us hope that vaccinations can change this sad predictions. The obtained results can be also useful for assessing the effectiveness of mass vaccination in Ukraine and other countries.

Very long duration of the pandemic requires correction of our behavior, we can not live as before it occurred. Decreased feelings of insecurity and non-compliance with social distancing may further increase the pandemic duration and the number of the coronavirus victims. Total closure of settlements or regions can be recommended only in the event of a sharp increase in the number of cases. There are many things that can be done without loss to the economy and our daily lives:

1. Minimize the number of contacts and trips, not visit crowded places. Work and study remotely where possible. 
2. Refrain from shaking hands and kisses during meetings. Use masks in transport and crowded areas.

3. If you (or others) have any suspicious symptoms, do your best to avoid the spread of the infection.

Acknowledgements: I would like to express my sincere thanks to Gerhard Demelmair, Anatolii Nikitin, Anatolii Podkur, and Oleksii Rodionov for their help in collecting and processing data.

Financial Support: This research received no specific grant from any funding agency, commercial or nonprofit sectors.

Conflict of Interests Statement: The author has no conflicts of interest to disclose.

Ethics Statement: This research did not required ethical approval.

\section{References}

[1] World Health Organization. "Coronavirus disease (COVID-2019) situation reports". https://www.who.int/emergencies/ diseases/novel-coronavirus-2019/situation-reports/.

[2] https://index.minfin.com.ua/ua/reference/coronavirus/ukraine/

[3] https://www.kmu.gov.ua/

[4] COVID-19 Data Repository by the Center for Systems Science and Engineering (CSSE) at Johns Hopkins University (JHU). https://github.com/owid/covid-19-data/tree/master/public/data

[5] Kermack WO, McKendrick AG. A Contribution to the mathematical theory of epidemics. J Royal Stat Soc Ser A. 1927;115:70021.

[6] Murray JD. Mathematical Biology I/II. New York: Springer; 2002.

[7] Langemann D, Nesteruk I, Prestin J. Comparison of mathematical models for the dynamics of the Chernivtsi children disease. Mathematics in Computers and Simulation. 2016;123:68-79. DOI: 10.1016/j.matcom.2016.01.003

[8] Nesteruk I. Statistics based models for the dynamics of Chernivtsi children disease. Naukovi Visti NTUU KPI. 2017;5:26-34. DOI: 10.20535/1810-0546.2017.5.108577

[9] Nesteruk I. Statistics-based predictions of coronavirus epidemic spreading in mainland China. Innov Biosyst Bioeng. 2020; 4(1):13-18. DOI: 10.20535/ibb.2020.4.1.195074.

[10] Nesteruk I. Characteristics of coronavirus epidemic in mainland China estimated with the use of official data available after February 12, 2020. [Preprint.] ResearchGate. 2020 Mar. DOI:10.13140/RG.2.2.19667.32804.

[11] Nesteruk I. Estimations of the coronavirus epidemic dynamics in South Korea with the use of SIR model [Preprint.] ResearchGate. 2020 Mar. DOI: 10.13140/RG.2.2.15489.40807.

[12] Nesteruk I. Comparison of the coronavirus epidemic dynamics in Italy and mainland China [Preprint.] MEDRXIV. 2020 March. DOI: https://medrxiv.org/cgi/content/short/2020.03.18.20038133v1

[13] Nesteruk I. Stabilization of the coronavirus pandemic in Italy and global prospects [Preprint.] MEDRXIV. 2020 March. DOI: https://medrxiv.org/cgi/content/short/2020.03.28.20045898v1

[14] Nesteruk I. Long-term predictions for COVID-19 pandemic dynamics in Ukraine, Austria and Italy [Preprint.] MEDRXIV, 2020 Apr. DOI: 10.13140/RG.2.2.31170.53448

[15] Nesteruk I. SIR-simulation of Corona pandemic dynamics in Europe. [Preprint.] MEDRXIV, 2020 Apr. DOI: https://medrxiv. org/cgi/content/short/2020.04.22.20075135v1

[16] Nesteruk I. Динаміка COVID-19 епідемії в Україні та Києві після покращання тестування. COVID-19 epidemic dynamics in Ukraine and Kyiv after testing has improved (In Ukrainian). [Preprint.] ResearchGate. 2020 Apr. doi: 10.13140/RG.2.2.36705.86885

[17] Nesteruk I. Hidden periods, duration and final size of COVID-19 pandemic. Preprint. MedRxiv. May 10, 2020. https://medrxiv. org/cgi/content/short/2020.05.10.20097147v1

[18] Nesteruk I. Simulations and predictions of COVID-19 pandemic with the use of SIR model. Innov Biosyst Bioeng, 2020, vol. 4, no. 2, 110-121, doi: 10.20535/ibb.2020.4.2.204274. http://ibb.kpi.ua/article/view/204274

[19] Nesteruk I. Coronasummer in Ukraine and Austria. [Preprint.] ResearchGate. 2020 June. DOI: 10.13140/RG.2.2.32738.56002

[20] Nesteruk I. COVID19 pandemic dynamics. Springer Nature, 2021, DOI: 10.1007/978-981-33-6416-5, https://doi.org/10.1007/978-981-33-6416-5

[21] PAGE E.S. On problems in which a change in a parameter occurs at an unknown point. Biometrika, Volume 44, Issue 1-2, June 1957, Pages 248-252, https://doi.org/10.1093/biomet/44.1-2.248 
[22] Wang Y.B., X Z Jia X.Z. and J Cheng J. Numerical differentiation method and its application to reconstruction of discontinuity. Inverse Problems. 2002. V.18, No. 6, 1461

[23] Wan X.Q., Wang Y.B. and M Yamamoto M. Detection of irregular points by regularization in numerical differentiation and application to edge detection. 2006. Inverse Problems, V.22, No. 3, 1089.

[24] Zhao Zh et al. A stabilized algorithm for multi-dimensional numerical differentiation. Journal of Algorithms \& Computational Technology, April 19, 2016, https://doi.org/10.1177/1748301816640450

[25] Draper NR, Smith H. Applied regression analysis. 3rd ed. John Wiley; 1998.

[26] https://onlinepubs.trb.org/onlinepubs/nchrp/cd-22/manual/v2appendixc.pdf

[27] https://podillyanews.com/2020/12/17/u-shkolah-hmelnytskogo-provely-eksperyment-z-testuvannyam-na-covid-19/

[28] https://www.pravda.com.ua/news/2020/11/12/7273372/

[29] Joseph T Wu, Kathy Leung, Gabriel M Leung. Nowcasting and Forecasting the Potential Domestic and International Spread of the 2019-nCoV Outbreak Originating in Wuhan, China: A Modelling Study. Lancet 2020 Jan 31. DOI: 10.1016/S01406736(20)30260-9

[30] Shi Zhao, Qianyin Lin, Jinjun Ran, Salihu S Musa, Guangpu Yang, Weiming Wang, Yijun Lou, Daozhou Gao, and others. Preliminary estimation of the basic reproduction number of novel coronavirus (2019-nCoV) in China, from 2019 to 2020 : A data-driven analysis in the early phase of the outbreak. International Journal of Infectious Diseases. Published online: January 30, 2020. DOI: https://doi.org/10.1016/j.ijid.2020.01.050

[31] Byass, P. Eco-epidemiological assessment of the COVID-19 epidemic in China, January-Februry 2020. medRxiv 2020, doi:10.1101/2020.03.29.20046565.

[32] Tang, B., Bragazzi, N. L., Li, Q., et al. "An updated estimation of the risk of transmission of the novel coronavirus (2019. nCov).” Infectious disease modelling, vol. 5, pp. 248-255. 2020 Feb. 11. doi:10.1016/j.idm.2020.02.001.

[33] Ying Liu, Gayle AA, Wilder-Smith A, Rocklöv J. The reproductive number of COVID-19 is higher compared to SARS coronavirus. Jurnal of Travel Medicine, Volume 27, Issue 2, March 2020, taaa021, https://doi.org/10.1093/jtm/taaa021

[34] Kucharski AJ. et al. Early dynamics of transmission and control of COVID-19: a mathematical modelling study. TheLancet Infectious Diseases (2020) Published:March 11, 2020 DOI: https://doi.org/10.1016/S1473-3099(20)30144-4

[35] Batista, M. "Estimation of the final size of the COVID-19 epidemic." [Preprint.] medRxiv. 2020 Feb. 28. https://www. researchgate.net/profile/Milan_Batista doi:10.1101/2020.02.16.20023606.

[36] J. Dehning et al. Inferring COVID-19 spreading rates and potential change points for case number forecasts. Preprint, ArXiv:2004.01105(2020).

[37] Chen Y, Cheng J, Jiang Y, Liu K. A time delay dynamical model for outbreak of 2019-nCoV and the parameter identification. ArXiv:2002.00418; 2020.

[38] Peng L, Yang W, Zhang D, Zhuge C,Hong L. Epidemic analysis of COVID-19 in China by dynamical modeling. ArXiv:2002.06563;2020.

[39] Chang SL, Harding N, Zachreson C, Cliff OM, Prokopenko M. Modelling transmission and control of the COVID-19 pandemic in Australia. ArXiv:2003.10218;2020.

[40] Maier BF, Brockmann D. Effective containment explains sub-exponential growth in confirmed cases of recent COVID-19 out break in mainland China. ArXiv:2002.07572;2020.

[41] Song PX, Wang L, Zhou Y, He J, Zhu B, Wang F, et al. An epidemiological forecast model and software assessing interventions on COVID-19 epidemic in China. MedRxiv. 2020;

[42] Chinazzi M, Davis JT, Ajelli M, Gioannini C, Litvinova M, Merler S, et al. The effect of travel restrictions on the spread of the 2019 novel coronavirus (COVID-19) outbreak. Science. 2020; 368(6489):395-400. https://doi.org/10.1126/science. aba9757PMID:32144116

[43] Zhang Y,Jiang B,Yuan J, Tao Y. The impact of social distancing and epicenter lockdown on the COVID-19 epidemic in mainland China: A data-driven SEIQR model study. MedRxiv. 2020;

[44] Noureddine Benlagha. Modeling the Declared New Cases of COVID-19 Trend Using Advanced Statistical Approaches. [Preprint.] ResearchGate. March 2020. DOI: 10.6084/m9.figshare.12052638

[45] Nesteruk I. The COVID-19 pandemic storm in India. [Preprint] medRxiv 2021. DOI: https://doi.org/10.1101/2021.05.06. 21256523

[46] Pongkaew Udomsamuthirun et al. The reproductive index from SEIR model of Covid-19 epidemic in Asean. [Preprint.] MEDRXIV, 2020 Apr. DOI: https://doi.org/10.1101/2020.04.24.20078287

[47] Pereira IG et al. Forecasting Covid-19 Dynamics in Brazil: A Data Driven Approach. Int. J. Environ. Res. Public Health 2020, 17(14), 5115; https://doi.org/10.3390/ijerph17145115

[48] Linka K., Peirlinck M., Kuhl E. The reproduction number of COVID-19 and its correlation with public health interventions. [Preprint.] MEDRXIV, 2020. DOI:10.1101/2020.05.01.20088047

[49] Distante, C.; Gadelha Pereira, I.; Garcia Goncalves, L.M.; Piscitelli, P.; Miani, A. Forecasting Covid-19 Outbreak Progression in Italian Regions: A model based on neural network training from Chinese data. medRxiv 2020.

[50] Hamzah, F.; Binti, A.; Lau, C.; Nazri, H.; Ligot, D.V.; Lee, G.; Tan, C.L. CoronaTracker: Worldwide COVID-19 Outbreak Data Analysis and Prediction. Bull. World Health Organ. 2020, 1, 32.

[51] Fanelli, D.; Piazza, F. Analysis and forecast of COVID-19 spreading in China, Italy and France. Chaos Solitons Fractals 2020, 134, 109761. 
[52] Webb, G.F.; Magal, P.; Liu, Z.; Seydi, O. A model to predict COVID-19 epidemics with applications to South Korea, Italy, and Spain. medRxiv 2020.

[53] Bastos, S.B.; Cajueiro, D.O. Modeling and forecasting the early evolution of the Covid-19 pandemic in Brazil. arXiv 2020, arXiv:2003.14288.

[54] Grant, A. Dynamics of COVID-19 epidemics: SEIR models underestimate peak infection rates and overestimate epidemic duration. medRxiv 2020.

[55] Loli Piccolomiini, E.; Zama, F. Monitoring Italian COVID-19 spread by an adaptive SEIRD model. medRxiv 2020.

[56] Baerwolff, G.K. A Contribution to the Mathematical Modeling of the Corona/COVID-19 Pandemic. medRxiv 2020.

[57] Distante, C.; Piscitelli, P.; Miani, A. Covid-19 Outbreak Progression in Italian Regions: Approaching the Peak by the End of March in Northern Italy and First Week of April in Southern Italy. Int. J. Environ. Res. Public Health 2020, 17, 3025.

[58] te Vrugt, M.; Bickmann, J.; Wittkowski, R. Effects of social distancing and isolation on epidemic spreading: A dynamical density functional theory model. arXiv 2020, arXiv:2003.13967.

[59] Yang, Z.; Zeng, Z.; Wang, K.; Wong, S.S.; Liang, W.; Zanin, M.; Liu, P.; Cao, X.; Gao, Z.; Mai, Z.; et al. Modified SEIR and Al prediction of the epidemics trend of COVID-19 in China under public health interventions. J. Thorac. Dis. 2020, $12,165$.

[60] Roda, W.C.; Varughese, M.B.; Han, D.; Li, M.Y. Why is it difficult to accurately predict the COVID-19 epidemic? Infect. Dis. Model. 2020, 5, 271-281.

[61] Otunuga, O.M.; Ogunsolu, M.O. Qualitative analysis of a stochastic SEITR epidemic model with multiple stages of infection and treatment. Infect. Dis. Model. 2020, 5, 61-90.

[62] K Chatterjee et al. Healthcare impact of COVID-19 epidemic in India: A stochastic mathematical model. Medical Journal Armed Forces India. Volume 76, Issue 2, April 2020, Pages 147-155.

[63] I Ciufolini, A Paolozzi. Mathematical prediction of the time evolution of the COVID-19 pandemic in Italy by a Gauss error function and Monte Carlo simulations. Eur. Phys. J. Plus (2020) 135: 355 https://doi.org/10.1140/epjp/s13360-020-00383-y

[64] S Annas et al. Stability analysis and numerical simulation of SEIR model for pandemic COVID-19 spread in Indonesia. Chaos, Solitons \& Fractals Volume 139, October 2020, 110072 https://doi.org/10.1016/j.chaos.2020.110072

[65] RP Yadav, R Verma A numerical simulation of fractional order mathematical modeling of COVID-19 disease in case of Wuhan China. Chaos, Solitons \& Fractals. Volume 140, November 2020, 110124 https://doi.org/10.1016/j.chaos.2020.110124

[66] KY Ng, MM Gui. COVID-19: Development of a robust mathematical model and simulation package with consideration for ageing population and time delay for control action and resusceptibility. Physica D: Nonlinear Phenomena.Volume 411, October 2020, 132599 https://doi.org/10.1016/j.physd.2020.132599

[67] B.Ivorra, M.R.Ferrández, M.Vela-Pérez, A.M.Ramos. Mathematical modeling of the spread of the coronavirus disease 2019 (COVID-19) taking into account the undetected infections. The case of China. Communications in Nonlinear Science and Numerical Simulation, Volume 88, September 2020, 105303, https://doi.org/10.1016/j.cnsns.2020.105303

[68] Nguyen HuyTuan, Hakimeh Mohammadi, Shahram Rezapour. A mathematical model for COVID-19 transmission by using the Caputo fractional derivative. Chaos, Solitons \& Fractals. 2020, 110107. https://doi.org/10.1016/j.chaos.2020.110107

[69] Musalula Sinkala, Panji Nkhoma, Mildred Zulu, Doris Kafita, Rabecca Tembo, Victor Daka. The COVID-19 Pandemic in Africa: Predictions using the SIR Model. medRxiv 2020.06.01.20118893; doi: https://doi.org/10.1101/2020.06.01.2011889

[70] Komi Agbokou1, Kossi Gneyou1, Kokou Tcharie. Investigation on the temporal evolution of the covid'19pandemic: prediction for Togo. Open Jornal of mathematical sciencies. 2020, 4, 273-279; doi:10.30538/oms2020.0118 https://pisrt.org/psrpress/journals/oms

[71] Gergő Pintér,Imre Felde,Amir Mosavi, Richard Gloaguen. COVID-19 Pandemic Prediction for Hungary; A Hybrid Machine Learning Approach. Mathematics 2020, 8, 890; doi:10.3390/math8060890 www.mdpi.com/journal/mathematics

[72] Cody Carroll et al.Time Dynamics of COVID-19. medRxiv 2020.05.21.20109405; doi: https://doi.org/10.1101/2020.05.21. 2010940

[73] Khaled M Furati, Ibrahim O. Sarumi, Abdul Q.M. Khaliq. Memory-Dependent Model for the Dynamics of COVID-19 Pandemic. medRxiv 2020.06.26.20141242; doi: https://doi.org/10.1101/2020.06.26.20141242

[74] Jurgen Bosch, Austin Wilson, Karthik O'Neil, Pater A Zimmerman. COVID-19 Predict - Predicting Pandemic Trends. medRxiv 2020.09.09.20191593; doi: https://doi.org/10.1101/2020.09.09.20191593

[75] Ali Asad, Siddharth Srivastava, Mahendra K. Verma. Evolution of COVID-19 Pandemic in India. medRxiv 2020.07.01.20143925; doi: https://doi.org/10.1101/2020.07.01.20143925

[76] Nawel Aries, Houdayfa Ounis. Mathematical Modeling of COVID-19 Pandemic in the African Continent. medRxiv 2020.10.10.20210427; doi: https://doi.org/10.1101/2020.10.10.20210427

[77] Felix Guenther, Andreas Bender, Katharina Katz, Helmut Kuechenhoff, Michael Hoehle. Nowcasting the COVID-19 Pandemic in Bavaria. medRxiv 2020.06.26.20140210; doi: https://doi.org/10.1101/2020.06.26.20140210

[78] Wan Yang, Jaimie Shaff, Jeffrey Shaman. COVID-19 Transmission Dynamics and Effectiveness of Public Health Interventions in New York City during the 2020 Spring Pandemic Wave. medRxiv 2020.09.08.20190710; doi: https://doi.org/10.1101/ 2020.09.08.20190710

[79] Ronald Dickman. A SEIR-like model with a time-dependent contagion factor describes the dynamics of the Covid-19 pandemic. medRxiv 2020.08.06.20169557; doi: https://doi.org/10.1101/2020.08.06.20169557

[80] Lakshmi Rani Kundu, Most. Zannatul Ferdous, Ummay Soumayia Islam, Marjia Sultana. Forecasting the spread of COVID19 pandemic in Bangladesh using ARIMA model. medRxiv 2020.10.22.20217414; doi: https://doi.org/10.1101/2020.10.22. 


\section{4}

[81] Diego Carvalho, Rafael Barbastefano, Dayse Pastore, Maria Clara Lippi. A novel predictive mathematical model for COVID-19 pandemic with quarantine, contagion dynamics, and environmentally mediated transmission. medRxiv 2020.07.27.20163063; doi: https://doi.org/10.1101/2020.07.27.20163063

[82] Md. Haider Ali Biswas, M. S. Khatun, A. K. Paul, M. R. Khatun, M. A. Islam, S. A. Samad, U. Ghosh. Modeling the Effective Control Strategy for Transmission Dynamics of Global Pandemic COVID-19. medRxiv 2020.04.22.20076158; doi: https://doi. org/10.1101/2020.04.22.20076158

[83] Elinor Aviv-Sharon, Asaph Aharoni. Forecasting COVID-19 pandemic Severity in Asia. medRxiv 2020.05.15.20102640; doi: https://doi.org/10.1101/2020.05.15.20102640

[84] Nayana Bannur, Harsh Maheshwari, Sansiddh Jain, Shreyas Shetty, Srujana Merugu, Alpan Raval. Adaptive COVID-19 Forecasting via Bayesian Optimization. medRxiv 2020.10.19.20215293; doi: https://doi.org/10.1101/2020.10.19.2021529

[85] Sewanou H. Honfo, Beaugard H. Taboe, Romain Glele Kakai. Modeling COVID-19 dynamics in the sixteen West African countries. medRxiv 2020.09.04.20188532; doi: https://doi.org/10.1101/2020.09.04.20188532

[86] Piotr T. Chruściel, Sebastian J. Szybka. Universal properties of the dynamics of the Covid-19 pandemics. medRxiv 2020.08.24.20181214; doi: https://doi.org/10.1101/2020.08.24.20181214

[87] BRAHMATHEJA REDDY MALI REDDY, ANUJ SINGH, PRADEEP SRIVASTAVA. COVID-19 TRANSMISSION DYNAMICS IN INDIA WITH EXTENDED SEIR MODEL. medRxiv 2020.08.15.20175703; doi: https://doi.org/10.1101/2020.08.15.20175703

[88] Jianping Huang, Xiaoyue Liu, Li Zhang, Kehu Yang, Yaolong Chen, Zhongwei Huang, Chuwei Liu, Xinbo Lian, Danfeng Wang. The amplified second outbreaks of global COVID-19 pandemic. medRxiv 2020.07.15.20154161; doi: https://doi.org/10.1101/ 2020.07.15.2015416

[89] Gyan Bhanot, Charles DeLisi. Analysis of Covid-19 Data for Eight European Countries and the United Kingdom Using a Simplified SIR Model. medRxiv 2020.05.26.20114058; doi: https://doi.org/10.1101/2020.05.26.20114058

[90] Mahmoud A. Ibrahim, Amenah Al-Najafi. Modeling, Control, and Prediction of the Spread of COVID-19 Using Compartmental, Logistic, and Gauss Models: A Case Study in Iraq and Egypt . Processes2020,8, 1400; doi:10.3390/pr8111400

[91] Gaetano Perone. Comparison of ARIMA, ETS, NNAR and hybrid models to forecast the second wave of COVID-19 hospitalizations in Italy (HEDG-WP 20/18, University of York). Preprint. http://www.york.ac.uk/economics/postgrad/herc/hedg/wps/

[92] Átila Madureira Bueno, Cristiane M. Batistela, Diego Paolo Ferruzzo Correa , J.R.C. Piqueira. SIRSi compartmental model for COVID-19 pandemic with immunity loss. Chaos Solitons \& Fractals, Oct 2020. DOI: 10.1016/j.chaos.2020.110388

[93] Ahmed E. Fahmya, Mohammed M. El-desoukya, Ahmed S.A. Mohamed. Epidemic Analysis of COVID-19 in Egypt, Qatar and Saudi Arabia using the Generalized SEIR Model. MedRxiv. Posted August 22, 2020. Doi: https://doi.org/10.1101/2020.08. 19.20178129

[94] Ryad Ghanam, Edward L. Boone, Abdel-Salam G. Abdel-Salam. SEIRD MODEL FOR QATAR COVID-19 OUTBREAK: A CASE STUDY. Posted 26 May 2020. arXiv:2005.12777v1 